\title{
ASIA PACÍFICO: ¿OPCIÓN ESTRATÉGICA DE DIVERSIFICACIÓN COMERCIAL DE MÉXICO ANTE LA RENEGOCIACIÓN DEL TLCAN?
}

\author{
Juan González García \\ Universidad de Colima \\ América Ivonne Zamora Torres \\ Universidad Michoacana de San Nicolás de Hidalgo
}

\section{INTRODUCCIÓN}

Desde el punto de vista de los procesos de integración económica y comercial impulsados en el mundo, particularmente luego de la creación del GATT-OMC (1947 el primero y 1995 la segunda), 2018 será recordado en la historia económica contemporánea como el año del parteaguas contra el pilar fundamental del paradigma neoliberal, construido en el mundo por los Estados Unidos de Norteamérica (EUA) desde inicios de la década de los ochenta del siglo XX: el neoliberalismo económico de libre mercado.

Dicho pilar, que es el del libre comercio o, más propiamente, el paradigma del mecanismo de mercado, se expresó y se sigue expresando en el mundo como el del poder del mercado sobre el poder del Estado, en la conducción económica de la economía nacional. Como se dijo, este modelo está siendo cuestionado al inicio de una estrategia global de cambio, quizá paradigmática, que principió con el discurso del presidente de la principal economía del mundo, Donald J. Trump, quien desde que asumió el poder, en enero de 2017, se ha mostrado como un gobernante antilibre mercado, por no decir antisistema, sobre todo porque considera que las políticas comerciales en favor del libre mercado le han significado una pérdida económica a la otrora poderosa economía de su país, que es una de las más, si no es que la más, deficitaria del mundo en términos de su comercio internacional (WTO, 2018: 6-13). 
De hecho, parte del discurso en contra del libre comercio se ha venido expresando desde 2017, cuando el presidente Trump firmó el decreto para "sacar" a los Estados Unidos del Acuerdo de Asociación Transpacífico (TPP, por sus siglas en inglés) que habían negociado doce países de la región transpacífica entre 2012 y 2016. Más adelante declaró la finalización del Tratado de Libre Comercio de América del Norte (TLCAN) si éste seguía afectando a su país, declaración que finalmente no se hizo efectiva al iniciar, en mayo de 2017, las negociaciones entre los representantes comerciales de Canadá y México, después de recolectar, de la opinión pública estadounidense, los temas a renegociar para que dicho país continuara en el tratado. Y finalmente, la decisión de imponer en 2018 aranceles de entre 10 y $25 \%$ al acero, aluminio e importación de autos a la Unión Europea y a China, y recientemente a México y Canadá, ha desatado la expectativa de una guerra comercial de dimensiones aún desconocidas (UNCTAD, 2018a).

Precisamente es la negociación para modernizar el TLCAN, según expresión del gobierno estadounidense, independientemente de los 30 capítulos incluidos y de su grado de avance entre mayo de 2017 y septiembre de 2018, lo que motiva este escrito y nos permite formular las siguientes preguntas: ¿Ante el avance de la renegociación del TLCAN, que por cierto va a entrar al proceso legislativo de los tres países luego de que, el 30 de agosto, EUA y Canadá aceptaron que el segundo se integrara al acuerdo comercial que ya habían iniciado EUA y México a principios del mismo mes, podrá México finalmente diseñar una estrategia política para realmente diversificar su comercio internacional? Si fuera así, la siguiente pregunta sería, ¿cuál sería su estrategia para realmente avanzar comercialmente en el Foro de Cooperación Económica Asia Pacífico?

Interesa también analizar la posible estrategia comercial mexicana, ya que México es un país que, dadas las condiciones críticas que vivió en la década de los ochenta, incursionó en el TLCAN contra natura y sin más estrategia que la sola apertura. En la actualidad, la renegociación aprobada por los ejecutivos de los tres países, así como el cambio de gobierno (2018-2024) que cíclicamente se presenta cada seis años, le brinda a México la oportunidad de diseñar y construir una política comercial estratégica para el nuevo siglo.

A priori, consideramos que, al lado del discurso y acciones en contra del libre comercio ya implementadas por EUA durante 2018, vuelven a ponerse en el centro del debate global los supuestos beneficios del modelo librecambista a escala tanto global como nacional, lo 
que a su vez abre la oportunidad a los países para redefinir sus condiciones económicas internas y no quedar indefensos e indefinidos en torno a la reforma al modelo de economía abierta que, quiérase o no, sigue estando acotada y comandada por los Estados Unidos.

Obviamente, quienes esto escriben consideran que la misma coyuntura, si bien está determinada por la estrategia de negociación estadounidense, le permite a México, considerando los casi 25 años de vigencia del TLCAN y su política comercial internacional, proponer una política comercial estratégica que le permita hacer realidad su aspiración de diversificar su comercio internacional a partir de una propuesta factible, para incorporar sus años de experiencia fallida en la búsqueda infructuosa de la diversificación comercial internacional, como la pretendida con la región transpacífica o de Asia Pacífico (González, 1994: 110-128).

Asimismo, intentaremos dar respuesta a las preguntas formuladas líneas arriba, en el ánimo de contribuir al debate, siempre necesario, en torno a cual sería la mejor estrategia de política comercial que debería seguir México, con o sin el TLCAN, de cara a los retos que le esperan, ya no digamos ante lo inesperado al finalizar la segunda década del presente siglo, sino ante la incierta tercera década, cuya característica es la existencia de una economía global cada vez más dinámica y compleja en la que el eje central de poder económico se consolida en la región asiática del Pacífico, para la cual se plantea la necesidad de diseñar una estrategia particular (González, 1995: 136-140).

Con base en lo anterior, el escrito quedará entonces estructurado de la siguiente manera: en un primer apartado revisaremos los resultados globales de la política comercial mexicana, incluyendo el TLCAN, resultantes de una determinada estrategia a favor del mercado y sustentada en el libre comercio; en segundo lugar, formularemos una propuesta tentativa de los componentes que a nuestro juicio debe incorporar una estrategia comercial para tener posibilidades de éxito en este mundo cambiante, y en tercer lugar, se propondrá el diseño de una estrategia particular para buscar la reinserción de México en la región transpacífica, toda vez que, por poner excesiva atención en la economía de los países del TLCAN, olvidamos elaborar una gran estrategia puntual hacia el resto del mundo y en particular hacia la región transpacífica, que es la región del mundo en la que se concentra más de $80 \%$ de nuestras relaciones comerciales, lo que nos ha dejado en la indefensión ante el embate competitivo de 
los principales países asiáticos. Una política comercial estratégica es necesaria para todo país que busque ser parte activa de la economía global actual.

\section{RESULTADOS DE LA ESTRATEGIA COMERCIAL}

\section{GLOBAL DE MÉXICO}

Los antecedentes de la política y la estrategia comercial mexicana de finales del siglo XX están incluidos en las crisis económicas de 1982, 1987 y 1994-1995, y en las primeras dos décadas del presente siglo: sus impactos dejaron entrever que gran parte de los problemas de la economía mexicana se debían a que la industria nacional no despegó como el gobierno esperaba, después de décadas de protección con el argumento de la industria nacional naciente. Luego de su incorporación en la economía global y de ésta en la economía nacional, se recrudecieron muchos de los problemas estructurales de México (Cárdenas, 2015: 640698).

Tales crisis, en resumidas cuentas, podrían sintetizarse en el hecho de que el sector agrícola, agotado después de décadas de ser soporte del sector industrial y, dentro de éste, del manufacturero, no despuntó como se esperaba: gran parte de la industria nacional se quedó en la indefinición propia del agotamiento del modelo sustitutivo de importaciones y sin una estrategia competitiva que le permitiera afrontar la competencia internacional que imperaba en el mundo, debido a que desde los ochentas se instauraron en el mundo políticas a favor del libre mercado y de la apertura y desregulación comercial internacional.

México no fue la excepción en cuanto al tipo de políticas a favor del libre mercado para paliar los efectos de la crisis de 1982, que fue el gran detonante para el cambio de rumbo y del modelo de desarrollo económico. Efectivamente, a partir de 1982 y entre 1983 y 1987 México realizó un ajuste a su modelo de desarrollo económico para orientarlo hacia el exterior con base en una política económica de menor participación del gobierno, pero sobre todo con un papel de mero expectador, para permitir y garantizar que el mecanismo de mercado contribuyera a restablecer los equilibrios perdidos en las principales variables macroeconómicas (Ortiz, 2009: 46-48).

De esta manera el gobierno redujo su papel a sólo facilitador del libre mercado, con políticas de desregulación, reprivatización y liberalización comercial y financiera, para 
apuntalar el nuevo modelo de desarrollo económico que haría del comercio internacional el nuevo motor de la economía y propiciar así, el resurgimiento del desarrollo económico sobre la base del crecimiento de las exportaciones y la mayor participación de las empresas privadas en la estructura del comercio internacional, vinculado ahora al Acuerdo General sobre Aranceles y Comercio (GATT, por sus siglas en inglés).

La finalidad de la nueva inserción internacional de México era hacerlo salir de la crisis mediante la diversificación de la estructura económica y del comercio exterior, transformarlo en una potencia exportadora y lograr que el libre comercio contribuya a modernizar el aparato productivo nacional. Estos objetivos se lograrín con el simple hecho de abrir la economía, desregularla y diseñar e implementar una política comercial.

Desde nuestro punto de vista, la política comercial internacional que implementó México fue una política de reacción ante el nuevo modelo de desarrollo económico con orientación externa, más que una política pre-elaborada, de otra manera no se explicaría la aceleración con la que se abrieron los principales sectores e industrias nacionales a la competencia internacional, ni se tendría una idea predeterminada en torno a los efectos de esa apertura acelerada sobre el aparato productivo nacional. Por decirlo de otra manera, se pensó, ingenuamente o no, que la sola apertura de la economía y de las políticas de reprivatización, de desregulación y de liberalización del mercado de capitales, sería suficiente para apuntalar al modelo promotor de exportaciones.

A partir de entonces la desgravación arancelaria fue condición sine qua non para, entre 1983 y 1987, desmantelar la estructura de protección comercial que imperó en la etapa semiautárquica (1945-1982) para posteriormente en 1986, adherirse al GATT, y a partir de ello fortalecer la orientación externa de la política comercial, la firma de acuerdos de libre comercio (ALC), dentro de los cuales el más importante fue y es el Tratado de Libre Comercio de América del Norte (TLCAN, o NAFTA, por sus siglas en inglés), firmado en 1992 y ratificado en 1993 con entrada en vigor el 1 de enero de 1994. A partir de entonces México ha firmado 12 ALC con 48 países, creyendo que la sola firma y el establecimiento de políticas y programas de promoción del comercio internacional y de las exportaciones iba a ser suficiente para convertir al país en una potencia exportadora (Herrera, 2004: 277-325). 
CUADRO 1. Acuerdos y tratados de libre comercio de México con el mundo

\begin{tabular}{|c|c|c|c|}
\hline \multirow{2}{*}{$\begin{array}{c}\text { Nombre de los Tratados de Libre } \\
\text { Comercio (TLC) }\end{array}$} & \multirow{2}{*}{ Países que lo integran } & \multicolumn{2}{|c|}{ Vigencia } \\
\hline & & Desde & Hasta \\
\hline TLCAN México-E.U.A-Canadá & México, Estados Unidos y Canadá. & $01 / 01 / 1994$ & Indefinido \\
\hline TLC Colombia - México & Colombia y México. & $01 / 01 / 1995$ & Indefinido \\
\hline TLC México-Bolivia & México y Bolivia. & $01 / 01 / 1995$ & Terminada \\
\hline TLC México-Costa Rica & Costa Rica y México. & $01 / 01 / 1995$ & Indefinido \\
\hline TLC México-Nicaragua & Nicaragua y México. & $01 / 07 / 1998$ & Indefinido \\
\hline TLC Chile - México & Chile y México. & $01 / 08 / 1999$ & Indefinido \\
\hline TLC México-Triángulo del Norte & México, El Salvador, Guatemala y Honduras. & $14 / 03 / 2000$ & Indefinido \\
\hline TLC Israel - México & Israel y México. & $01 / 07 / 2000$ & Indefinido \\
\hline TLCUE UE - México & $\begin{array}{l}\text { México, Unión Europea, Austria, Bélgica, Bulgaria, Croacia, } \\
\text { Chipre y República Checa, Dinamarca, Estonia, Finlandia, } \\
\text { Francia, Alemania, Grecia, Hungria, Irlanda, Italia, Letonia, } \\
\text { Lituania, Luxemburgo, Malta, Países Bajos, Polonia, Portugal, } \\
\text { Rumania, República Eslovaca, Eslovenia, España, Suecia y } \\
\text { Reino Unido. }\end{array}$ & $01 / 07 / 2000$ & Indefinido \\
\hline $\begin{array}{l}\text { TLC México- Asociación Europea de } \\
\text { Libre Comercio (AELC) }\end{array}$ & México, Islandia, Liechtenstein, Noruega y Suiza. & $01 / 07 / 2001$ & Indefinido \\
\hline TLC México - Uruguay & México y Uruguay. & $15 / 07 / 2004$ & Indefinido \\
\hline $\begin{array}{l}\text { Acuerdo para el fortalecimiento de la } \\
\text { asociación económica Japón - México }\end{array}$ & Japón y México. & $01 / 04 / 2005$ & Indefinido \\
\hline \begin{tabular}{|l|} 
Acuerdo de Integración Comercial \\
Perú - México \\
\end{tabular} & México y Perú. & $01 / 02 / 2012$ & Indefinido \\
\hline TLC México - Centroamérica & $\begin{array}{l}\text { Costa Rica, El Salvador, Guatemala, Honduras, México y } \\
\text { Nicaragua. }\end{array}$ & $01 / 09 / 2012$ & Indefinido \\
\hline TLC México - Panamá & México y Panamá. & $01 / 07 / 2015$ & Indefinido \\
\hline $\begin{array}{l}\text { México-Mercado Común del Sur } \\
\text { (MERCOSUR) }\end{array}$ & México, Argentina, Brasil, Paraguay y Uruguay. & $28 / 12 / 2016$ & Indefinido \\
\hline Alianza del Pacífico & Chile, Colombia, México y Perú. & $01 / 05 / 2016$ & Indefinido \\
\hline
\end{tabular}

FUENTE: Elaboración propia con información de (SICE, 2018; OMC, 2018; Subsecretaría de Comercio Exterior, 2018a; SICAIT, 2018).

Lo que siguió no se podría calificar como un fracaso total en las metas esperadas, aunque la mayoría de los resultados fueron adversos. En general, no se logró un crecimiento económico alto ni sostenido (se esperaba un crecimiento económico de 5\% anual); ni se generaron los empleos que se prometieron (alrededor de un millón a un millón doscientos mil por año). Se pretendía propiciar la modernización del aparato productivo, hacer más eficiente al campo, incorporar a las pequeñas y medianas empresas a la base exportadora, atraer más capitales extranjeros y más empresas globales al país, mantener la estabilidad macroeconómica (principalmente la estabilidad de precios), y diversificar las exportaciones y los bienes que conforman la base exportadora mexicana (Esquivel, 2012: 17-20). 
GRÁFICAS 1a y 1b. Participación de las exportaciones por tipo de bienes,

$1990-2016$
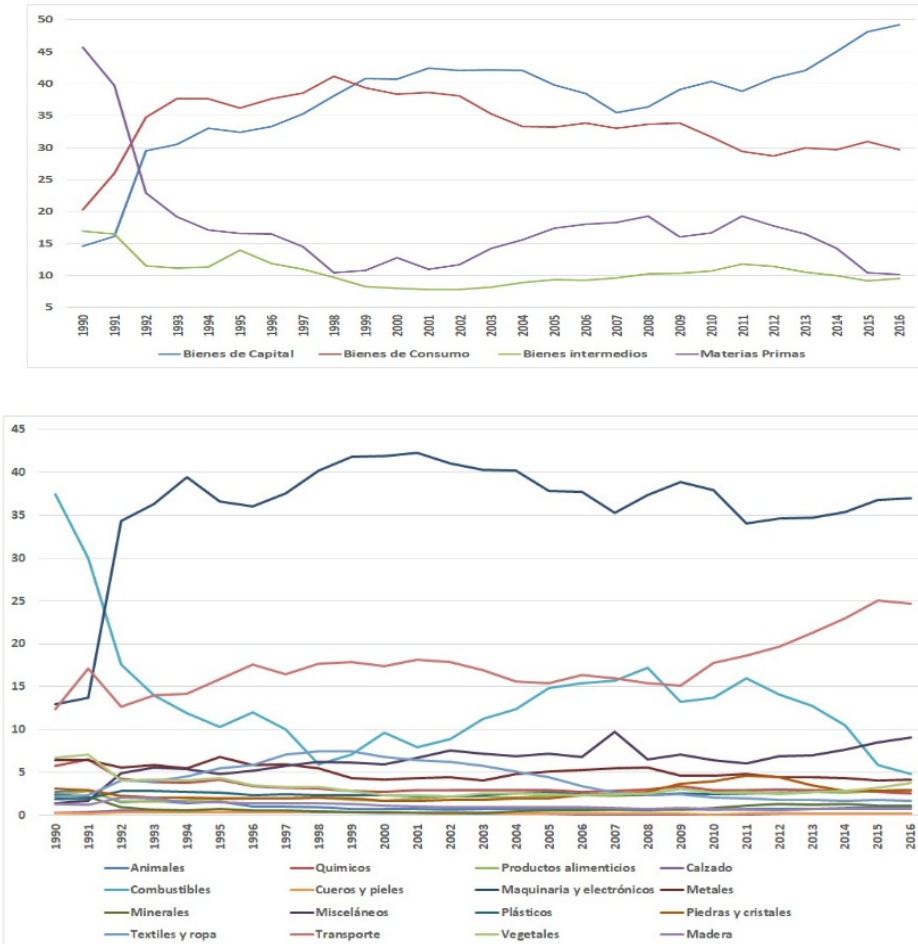

FUENTE: Elaboración propia con datos del WITS (2018).

Para los propósitos de este escrito, la política comercial internacional no logró su cometido, particularmente en relación con: a) convertir al comercio internacional en el nuevo motor de crecimiento y desarrollo económico; b) transformar la base y la estructura exportadora del país; $c$ ) reducir la dependencia del exterior; d) lograr una diversificación comercial; e) obtener los beneficios de la nueva orientación externa del modelo, entendiendo por ello alcanzar un balance comercial superavitario (Puyana y Romero, 2004: 395-411).

En términos generales, entre 1994 y 2017 la tasa de crecimiento promedio del PIB fue de $2.4 \%$, destacando la debilidad del sector industrial, que no generó efectos de arrastre sobre el resto de los sectores. La tasa de generación de empleos fue de alrededor de 400 mil por año, con un déficit de aproximadamente 12 millones de éstos para satisfacer las demandas existentes de la población económicamente activa, un problema adicional fue que, acorde con la política salarial restrictiva, los salarios reales no mostraron ninguna mejoría, ya que la pérdida de poder adquisitivo del salario acumuló 60\% en el periodo 1994-2017. 
Obviamente se argumentó que el TLCAN no iba a resolver todos los problemas de la economía, pero sí prometió mejores salarios y más empleos. En lo general, otras variables clave de la economía, tales como la IED, el tipo de cambio, la tasa de interés, las propias finanzas públicas, mostraron un comportamiento mediocre, impidiendo con ello, o más bien apoyando, el magro comportamiento de la economía.

En lo concerniente a la vinculación internacional y a la apertura de la economía, los resultados tampoco han sido satisfactorios, pues no se ha logrado reducir la dependencia del exterior, pensando, por ejemplo, que el modelo de orientación externa opera fundamentalmente anclado a las importaciones, de ahí su déficit (gráfica 2). Es decir, el boom de las exportaciones que experimentó la economía mexicana se da en gran medida debido al alto porcentaje de importaciones que contienen las exportaciones, principalmente de los sectores industrial y manufacturero, y al hecho de que en su gran mayoría son reexportaciones de las sucursales de las transnacionales que operan en el país.

GRÁfICA 2. Saldo del comercio exterior de México, 1971-2017

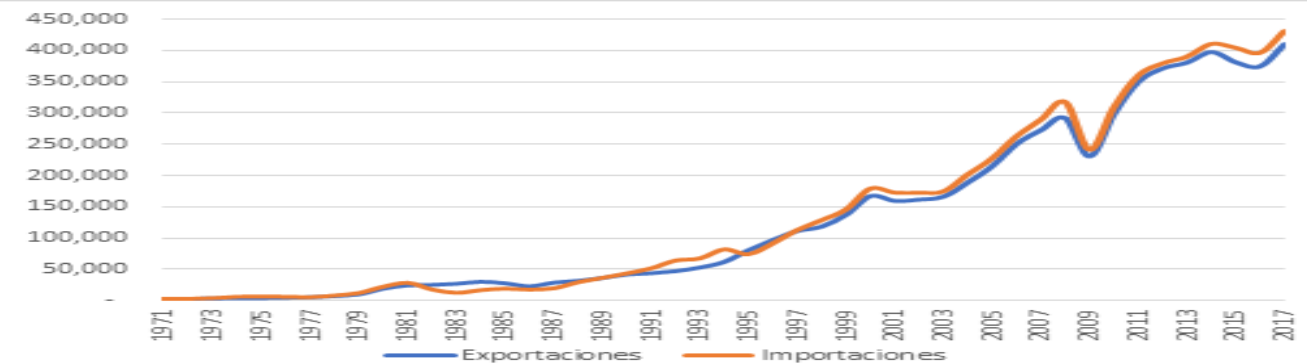

FUENTE: Elaboración propia con datos de UNCTAD Stat (2018).

La apertura, y más que ésta el TLCAN, desempeñó un papel fundamental para que México no lograra diversificar sus exportaciones en términos de bienes y/o servicios, no así de países, ya que tanto por los doce acuerdos comerciales como por mantener relaciones comerciales con la mayoría de los países miembros de la OMC, éstas se dirigieron a más de cien países, con el mayor porcentaje en EUA y el menor en Canadá.

Además, si bien es cierto que la base exportadora se transformó con el sector industrial liderando el comercio exterior, las exportaciones fueron más bien, como ya se dijo, reexportaciones (incluyendo las de la industria maquiladora) de transnacionales, 
exportaciones de bienes tradicionales con bajo nivel tecnológico y poca sustituibilidad no obstante pertenecer al sector industrial.

GRÁFICA 3. Exportaciones por sector económico de México

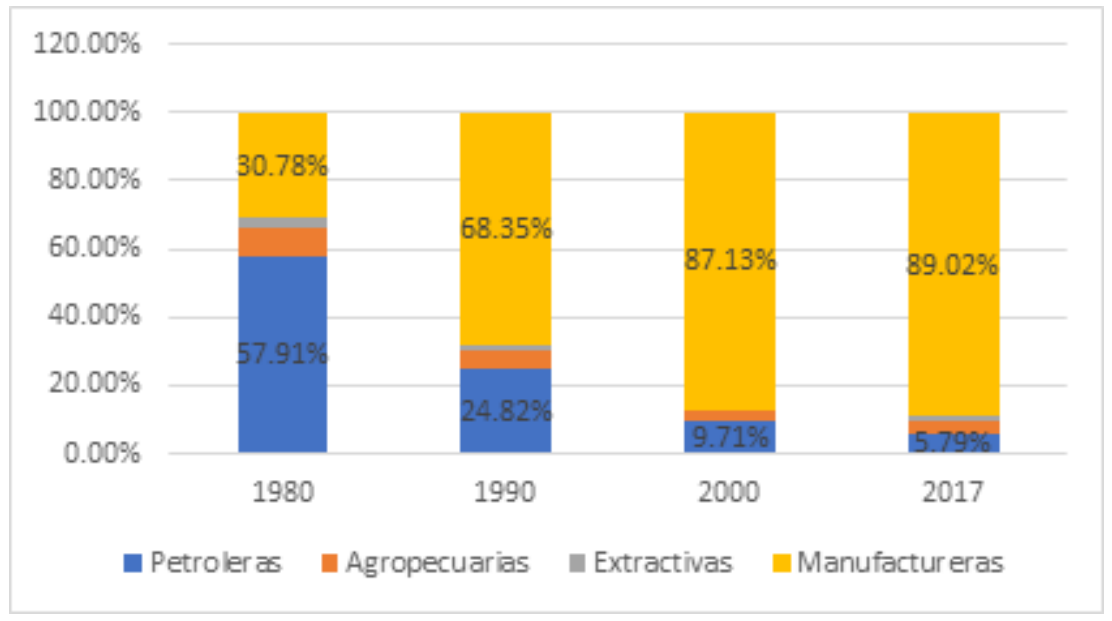

FUENTE: Elaboración propia con datos de Banxico (2018a, 2018b).

De este modo, las exportaciones del TLCAN se conformaron para ser dirigidas a un espacio geográfico específico, incentivadas por la alta elasticidad de la demanda, particularmente a causa de la continua depreciación del tipo de cambio y de la contigüidad geográfica, lo que implica bajos costos de negociación y de transportación. A final de cuentas todo ello reforzó el cúmulo de factores que incidieron en la acentuación de la dependencia de las exportaciones mexicanas hacia los países del TLCAN, principalmente Estados Unidos.

Con lo anterior se confirmó que si bien el TLCAN fue el principal instrumento para buscar la diversificación comercial internacional, también, paradójicamente, se convirtió en el principal obstáculo para logarla, debido, entre otros tantos, a los siguientes factores: a) cercanía geográfica, b) vínculos históricos, $c$ ) costos de transporte, $d$ ) costos de negociación, e) costos logísticos, f) incentivos arancelarios, $g$ ) factores culturales, y $h$ ) ideología en favor del libre mercado, la cual reforzó la dependencia de México hacia los Estados Unidos.

Ahora bien, la concentración del comercio exterior de México con EUA fue el mayor impedimento para que el país pudiera diseñar, estructurar, implementar y llevar a cabo una política comercial internacional estratégica que le permitiera diversificar su comercio internacional y, a la postre, convertirse en la principal justificación para no realizar la tarea de crear una estrategia comercial integral que propiciara una combinación de política 
industrial-comercial que pudiera soportar la nueva orientación externa del modelo exportador mexicano.

GRÁFICA 4. Evolución de las importaciones y exportaciones de México en el marco del TLCAN, 1993-2017

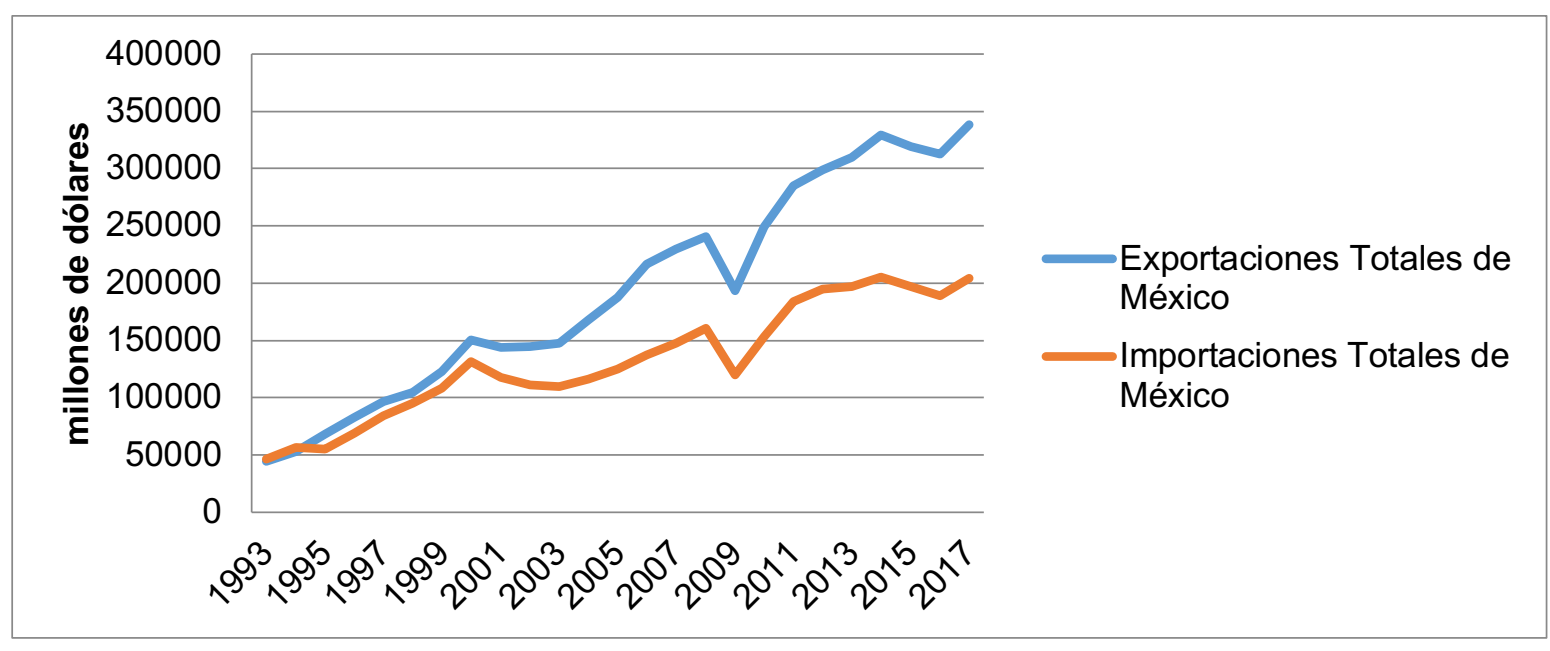

FUENTE: Elaboración propia con datos de la UNCTAD (2018c).

La crítica fundamental que hicieron algunos estudiosos del modelo de economía abierta mexicano (Calva, 2007: 11-20; Ruiz, 2011: 3-10; Ortiz, 2009: 53-55; Heras y Gómez, 2017: 81-84; Moreno Brid, 2016: 65-70), se refirió a la escasa vinculación entre los sectores y la industria exportadores con el resto del aparato productivo, propiciada por la ruptura de las cadenas de producción industrial, de soporte y, recientemente, de valor de la actividad industrial. Además de que la industria maquiladora de exportación pronto perdió competitividad a causa de la competencia entre industrias, mercados y capitales que impusieron las corporaciones transnacionales a los países receptores de dicha modalidad de inversión para reexportación.

\section{LA POLÍTICA COMERCIAL INTERNACIONAL EN UNA PERSPECTIVA ESTRATÉGICA}

Es diversa la bibliografía que analiza lo que es y/o debe ser una política comercial estratégica. Dicha política no está muy alejada de la tradición cepalina de la década de los cincuenta del siglo pasado (Rodrik, 2008: 25). No sólo se debe enfocar a la creación de condiciones para 
que el sector privado o la empresa privada se inserte en los flujos comerciales internacionales o bien en las firmas de acuerdos comerciales preferenciales para determinadas industrias y/o sectores; no, debe ir más allá, dicha política debe orientarse a la generación del conjunto de condiciones económicas para aprovechar las ventajas comparativas y competitivas con que cuentan los países, en una perspectiva dinámica (Rodrik, 2005: 7-23).

Desde el punto de vista histórico, los países que han logrado generar una base exportadora relevante, y que por ende han tenido éxito en su comercio internacional, han entendido que no basta con que el gobierno lleve a cabo una política comercial internacional basada en la diplomacia comercial, sino que ésta debe ir acompañada de un plan integral que permita al país en cuestión generar las condiciones necesarias para tener una base comercial dinámica, que pueda adaptarse al complejo comercio internacional que desde finales del siglo XX priva en el mundo (Krugman et al., 1995: 327-353).

Si bien desde el mercantilismo muchos países han establecido políticas comerciales estratégicas, la idea misma de estratégica se ha relacionado principalmente sólo con la acción del gobierno para buscar la construcción de una base exportadora sobre la base de las dotaciones con que cuenta el país en cuestión, lo que en definitiva no es del todo cierto. Una política comercial se vuelve estratégica cuando logra hacer converger los intereses públicos y los privados para consensar sobre lo que se va a producir y a quién o hacia dónde exportar; esto requiere que todos los sectores interesados en volverse exportadores estén efectivamente involucrados.

En la década de los noventa, y a propósito del resurgimiento tanto de la nueva teoría del crecimiento económico como del comercio internacional e incluso de la nueva geografía económica (Krugman, 2011:2-5), volvió a tomar relevancia el hecho de plantear la necesidad de que los países cuenten con una política comercial estratégica, pero en un sentido moderno; es decir, una política comercial que se adapte a las condiciones cambiantes de la economía y el comercio internacional; pero sobre todo, se parte del hecho de que en la economía internacional son las grandes corporaciones transnacionales las que determinan, en última instancia, qué y cómo comerciar.

Una política comercial estratégica, desde nuestro punto de vista, tiene que ver con un conjunto de condiciones que están lógicamente entrelazadas para incrementar las posibilidades de éxito en el mundo actual, complejo e hiper competitivo. Las siguientes son 
algunas de dichas condiciones, no limitativas ni restringidas, que a manera de subpolíticas de la política comercial estratégica se proponen en este escrito:

a) Dirección del gobierno en el proceso de inserción internacional.

b) Participación activa del sector privado en la economía.

c) Incorporación de las regiones en los procesos productivos.

d) Definición de las reglas del juego para las políticas de inversión público-privadas y totalmente privadas.

e) Determinación de regiones, países, territorios y mercados metas.

f) Política de innovación.

g) Política de construcción de infraestructura física.

h) Política comercial congruente.

i) Política de diversificación real de mercados globales.

j) Política industrial proactiva.

k) Política económica comprehensiva.

l) Política y plan de desarrollo de TIC.

m) Política de desarrollo, ciencia y tecnología.

n) Política de conformación de tetrahélice.

o) Política de captación de IED.

p) Políticas de estímulo a la productividad factorial.

q) Políticas educativas para el desarrollo de talento humano.

r) Determinación de zonas económicas especiales.

s) Conformación de racimos neoindustriales tipo parque de desarrollo científico tecnológico.

t) Creación de una institución encargada del seguimiento y monitoreo de las políticas, estrategia y acciones para garantizar el éxito de la política comercial estratégica nacional.

Es obvio que no existe un modelo a seguir respecto a cuáles son las subpolíticas principales que caracterizan a una política comercial estratégica en el sentido que aquí se propone, lo que sí es seguro es que éstas deben ser integrales y lo más interconectadas posibles, ya que en su conjunto deberán conformar la base de esta nueva política comercial, flexible, prospectiva, adaptativa y vanguardista, pues de lo que se trata es que no sea rebasada 
rápidamente por los cambios que se suscitan revolucionariamente en la esfera económica global y, por ende, no caigan en la obsolescencia.

Del conjunto de políticas aquí propuestas para hacer frente a la economía global competitiva, de inicio, son muy importantes cinco: 1) de diversificación de mercados, 2) económica comprehensiva, 3) industrial proactiva, 4) de inversión en educación, ciencia y tecnología, y finalmente, 5) de inserción de las regiones en el conjunto de la política industrial-comercial. Todas ellas deben ser impulsadas principal y obligatoriamente por el Estado, pero también deben ser consideradas por las empresas, que son las que hacen o no que dichas subpolíticas sean efectivas. A continuación describimos y analizamos en qué consiste cada una de éstas y por qué se seleccionaron de entre el cúmulo de subpolíticas de la política comercial estratégica que aquí se propone.

\section{Diversificación de mercados}

La política de diversificación de mercados es la principal y más conocida de las políticas comerciales que impulsan los gobiernos, y aunque en teoría la mayoría de países considera que sí la realiza, en los hechos son muy pocos los que lo logran efectivamente, teniendo como beneficio una menor tendencia a concentrar en unos cuantos países sus mercados de exportación. Esta política generalmente se refiere al conjunto de instrumentos, acuerdos, programas y acciones que buscan incentivar y expandir el alcance y cobertura para los productos de las empresas locales y/o nacionales en los mercados externos.

Lamentablemente muchas de estas políticas, si acaso, sólo fundamentan sus decisiones en lo limitado de las teorías ortodoxas del comercio internacional, que con base en el principio de las ventajas comparativas y la especialización ricardiana creen que eso va a ser suficiente para conquistar, por así llamarlo, el mercado internacional. No hay nada más falso que ello, particularmente en una economía global, compleja, hiper dinámica, donde la tecnología y las innovaciones están cambiando constantemente e impactando, por ende, los flujos del comercio internacional.

Ahora bien, la política de diversificación comercial debe ser más que instrumentos comerciales; aunque suene paradójico, debe ser una política dual: interna externa, que sintetice la mejor combinación de sí, los instrumentos y acuerdos comerciales globales, con las políticas y disposiciones nacionales que propicien el surgimiento, desenvolvimiento y 
fortalecimiento de una base exportadora nacional dinámica que se adapte prontamente a las exigencias del cambiante mercado global y de destinos específicos.

Por principio de cuentas, la política comercial estratégica, en lo relacionado con la diversificación comercial, debe expresarse en un documento tipo libro blanco en el que se defina lo que es y lo que pretende llevar a cabo, desde el punto de vista de su factibilidad. No debe ser un conjunto de reflexiones, listado, clausulado o articulado y buenas intenciones; no, debe ser formal, pragmático y pormenorizado, en el que se manifieste el conocimiento que se tiene respecto al entorno que rodea al comercio internacional de bienes y servicios a escala global, y debe contener, obviamente, metas, objetivos, estrategias, acciones, mercados, sectores, perfiles de consumidores (así sea de manera general), regiones tanto nacionales como externas a considerar, y en fin, todas aquellas actividades, actores e instituciones que hagan factible el surgimiento de una verdadera política de diversificación comercial.

\section{Política económica comprehensiva}

Una política económica comprehensiva es una combinación de reglas más cierto grado de discrecionalidad, si el momento lo justifica; pero sobre todo debe ser congruente con la de diversificación comercial, y a la inversa: dicha política debe conjugar los objetivos fundamentales del crecimiento económico con la estabilidad de precios, la creación de empleo y los equilibrios fiscal y comercial. Obviamente, y sabiendo que en términos de prioridad de los objetivos de la política económica no hay un orden predeterminado, se debe poner énfasis en dos de ellos: el equilibrio comercial y el crecimiento económico.

Si bien la teoría pura del comercio internacional tradicional consideraba que el comercio internacional por sí solo puede convertirse en motor del crecimiento económico, ello está supeditado a qué tanto, en verdad, logre transformarse en una locomotora que arrastre a toda la economía. Thirlwall (2011: 310-330), Perrotini y Vázquez (2018: 411-432) y Ocegueda (2007: 95-110), han demostrado cómo el comercio internacional implica problemas de balanza de pagos, si hay dependencia de importaciones; si no, hay un involucramiento sector-regional del comercio, y finalmente, hay competencia imperfecta en las empresas exportadoras, lo que hace que los frutos del comercio internacional no permeen como predice la teoría. 
Incluso, según la tradición clásica ya lo había previsto, se ha demostrado que el comercio internacional depende del crecimiento económico y no a la inversa (Perrotini y Vázquez, 2018: 426-430; Mortimore et al., 2000: 15-30); esto, obviamente, pone en tela de juicio los dogmas en torno a las bondades del libre comercio internacional per se, lo cual significa que es necesario retomar las políticas y las estrategias de crecimiento económico para que la estructura productiva pueda, efectivamente, dinamizarse para producir los bienes y servicios que demanda tanto la economía nacional como la internacional.

Por lo anterior, el tema de fondo del que se está hablando sería una de las subpolíticas listadas líneas arriba; la política industrial proactiva. En efecto, los países que han tenido éxito en su incorporación internacional a los mercados de bienes y servicios son los que han logrado implementar una política industrial proactiva, en un sentido moderno no acorde con la tradición proteccionista (Calderón y Sánchez, 2012: 131-133); es decir, una política industrial proactiva capaz de potenciar los recursos productivos, naturales, tecnológicos, regionales y humanos con que cuentan los países para incursionar en la economía internacional con sus cadenas globales de valor y de suministro, sobre la base de las ventajas comparativas reveladas dinámicas y nunca más las ventajas comparativas estáticas.

El papel que ejerce el gobierno para el diseño e implementación de esta política es fundamental para lograr los objetivos del crecimiento económico. Obviamente, de manera paralela se promueve también una política industrial proactiva para la economía de los servicios, que es el sector en el que en las últimas décadas se está concentrando el grueso del valor monetario de la economía (González y Meza, 2008: 769-779).

\section{Industrial proactiva}

Esta política es diferente a la utilizada en el siglo XIX o incluso en el XX, cuando de manera directa y abierta los gobiernos definían sus estrategias de crecimiento y desarrollo económico sobre la base de una política industrial a ultranza y a partir de la dotaciòn de recursos y la imitación de lo que hacían otros países con iniciativas innovadoras y, sobre todo, en contextos poco habituados a los cambios revolucionarios, según Schumpeter (1978: 15-101).

En la actualidad, hablar de una política industrial es concebir a ésta como una nueva visión del futuro en la que el Estado observa al sector industrial como generador de valor y base de la transformación y consolidación productiva; lo que cambia son las combinaciones 
de actores, recursos y alianzas público-privados, no la aspiración de convertir a la nación en una economía modernamente industrializada. En términos de Rodrik, es necesaria una política industrial para el nuevo siglo (2004: 1-15).

Es decir, el Estado dirige y coordina un conjunto de acciones y estrategias que permiten el redespegue neoindustrial de países que aún no logran consolidar sus estructuras industriales. Esto significa que ahora el conjunto de combinaciones antes mencionados se preocupa por generar las bases estructural-institucionales para lograr ese nuevo desarrollo industrial; un nuevo desarrollo industrial, que prepondere las actividades generadoras de valor, como son las de base tecnológica, de TIC, de procesos altamente mecanizados y de servicios financieros y bancarizados (Martínez y Ocampo, 2011: 15-39). Ya no más, estimular actividades tradicionales en las que los países emergentes han estado especializándose por siglos: actividades primarias, mineras y extractivas (UNCTAD, 2018d: 312; Cimoli, Dosi y Stiglitz, 2017: 469-480).

De lo que se trata ahora, eso sí, con la conducción y coordinación del Estado, que no cambia ni debe cambiar en su proceder, es de crear una base neoindustrial que permita el desarrollo de actividades de base tecnológica, de optimización de recursos humanos, creación de nuevos vocacionamientos productivos, reconstrucción de cadenas de valor o generación de nuevas, y uso masificado de las Tecnologías de la información y la comunicación.

Para que surja y logre consolidarse esa industria proactiva se necesita, también, crear las sinergias institucionales, para que los actores locales y regionales interactúen con las autoridades centrales o federales en términos de recursos, proyectos, financiamiento, mercados y sectores a desarrollar para el fortalecimiento de la base industrial y del sector exportador. De no hacerse esto, únicamente se estarán repitiendo errores del pasado, que en poco o nada apoyaron los proyectos de desarrollo industrial, como ocurrió en muchos países, particularmente de los llamados emergentes.

\section{Inversión en educación, ciencia, tecnología, y más innovación $(E C T+i)$}

La educación desde siempre, no sólo en la ciencia económica sino en otras disciplinas científicas, ha sido considerada la herramienta o instrumento fundamental para cambiar la estructura productiva de un país, propiciar la movilidad social, hacer eficientes a las 
instituciones y, sobre todo, preparar a las generaciones para la recepción de la herencia cultural, histórica, política y científica de un país, entre otros. Sin embargo, también tiene la función de preparar los cuadros profesionales que hagan posible el surgimiento de profesionales que se involucren, y sean involucrados, en el proceso productivo de nuevo cuño.

La educación, sobre todo la de nivel superior, en la parte del desarrollo de saberes y habilidades al puro estilo smithiano, puede ser el artífice de la política comercial estratégica en tanto que el sistema educativo nacional, independientemente de la carrera profesional que elijan los alumnos, forme estudiantes comprometidos con el sector productivo, al estudiar con mentalidad transformadora los hábitos, rutinas y métodos obsoletos que han impedido al sector productivo modernizarse y ser competitivo a escala global.

Con lo que aquí se plantea, no se está proponiendo una revolución educativa, sino una transformación a fondo de los métodos de enseñanza para ponerlos más ad hoc a las necesidades tanto del sector productivo, particularmente el de las industrias tecnológicas modernas, como del sector social y el de gobierno; es decir, formar profesionales que cada vez más respondan a las necesidades del entorno nacional y contribuyan a hacer más competitivo al sector productivo del país y, en el caso que nos ocupa, a la base exportadora nacional, que lógicamente estará más fortalecida y tendrá más posibilidades de tener éxito en la competencia global por los mercados de bienes y servicios.

En este mismo tenor, se requiere que la inversión en ciencia, tecnología e innovación sea bien dirigida hacia los sectores más modernos y dinámicos. Ya no es posible seguir canalizando recursos a áreas y sectores en los que no hay resultados concretos en términos del aparato productivo y de la base exportadora. Esto no se debe malinterpretar, no se trata de hacer una ciencia, tecnología e innovación mercantilista, sino que una parte de ésta debe vincularse formalmente con los objetivos de la política industrial proactiva, que será fundamental para que, finalmente, la política de diversificación comercial tenga mayores posibilidades de éxito.

Obviamente, la tradición nacional de pensar en una ECT $+\mathrm{i}$ al viejo estilo napoleónico de investigar per se y de no atreverse a proponer nuevos métodos de vinculación gobierno + universidad + industria + sociedad deben dejarse atrás para adecuar estas estructuras (las de ECT $+\mathrm{i}$ ) a las nuevas realidades del país que le exigen más atención y 
tentativas de respuesta y solución a los múltiples problemas de la sociedad y de los sectores productivos.

\section{Incorporación de las regiones a la transformación exportadora}

Quizás una subpolítica que no ha sido considerada en la estrategia de apertura comercial irrestricta ha sido ignorar que el territorio y las regiones económicas son dinámicas y no estáticas, tal y como lo plantea Boisier (2007: 185). En el pasado, con una visión centralista y estática se definieron e impulsaron planes y programas de desarrollo industrial que no tuvieron en cuenta que dichas regiones son dinámicas y que, dada la complejidad de la internacionalización de los procesos productivos, se requiere incorporarlas desde una perspectiva actual: las regiones son entes vivientes dónde se llevan a cabo la mayoría de los procesos productivos y competitivos (Bendesky, 1994: 982-988).

Las regiones, pues, representan el locus en el que se desarrollan las actividades productivas, sean éstas realizadas en áreas rurales o urbanas, dedicadas a la producción de bienes industriales o bienes primarios. Dependiendo de dónde se definan las actividades de mayor valor agregado, éstas pueden o no coadyuvar al crecimiento económico sectorial y hacer converger o divergir a las regiones (Ocegueda y Ríos, 2017: 750-565), de ahí la importancia que éstas adquieren si se trata de impulsar una política comercial estratégica, ya que, dependiendo del tipo de industrias, productos y mercados en que se pretenda incursionar, estas regiones podrán hacer más o menos factible dicho objetivo.

Una nueva regionalización no debe descartarse, toda vez que el nuevo regionalismo no responde ya únicamente a factores de contigüidad o de ubicación geográfica; ésta depende de los nuevos proyectos de desarrollo económico y regional, pero desde la perspectiva de las nuevas teorías y enfoques del desarrollo regional, que ven en la tetra hélice y en el potencial de los recursos humanos y naturales, de los mercados externos y de la interacción entre los agentes económicos, la gran oportunidad para redefinir a las regiones por su integración a un todo que pretende transformar a los territorios y economías otrora "vocacionadas", hacia determinada actividad, explicada únicamente por sus dotaciones naturales y según un plan diseñado desde los centros de poder de decisión económica. 


\section{ASIA-PACÍFICO: ¿OPCIÓN DE POLÍTICA COMERCIAL ESTRATÉGICA}

\section{INTERNACIONAL?}

Desde que se dio la reinserción de México a la economía internacional, a inicios de la década de los ochenta, dos de sus grandes problemas, como se vio en la sección anterior, los constituyó el déficit crónico de la cuenta corriente de la balanza de pagos, y depender de un solo mercado internacional. Dicho déficit se explica principalmente porque México carecía de una política comercial internacional estratégica que complementara la apertura comercial y financiera de su economía, así como su estrategia de firma de acuerdos de libre comercio y de asociación y complementariedad económica, como con Japón en 2005, que si bien brindaron a las empresas mexicanas la posibilidad de comerciar con 48 mercados en igual número de países, ello no fue suficiente para realmente vincular a las empresas mexicanas con esas economías.

Derivado de esa apertura sin estrategia real que le acompañara, lógicamente el país fue presa fácil de las estrategias exportadoras que desarrollaron muchos países, particularmente los de la región asiática, que desde la década de los sesenta empezaron a formar parte del llamado modelo asiático de desarrollo, el cual fincó parte de su éxito económico en su sector externo, que dinamizó en gran medida a los países de la región.

De hecho, casi coincidente con el periodo de inicio del TLCAN, la relación de México con Asia-Pacífico se dio en el contexto de su membresía con el llamado Mecanismo de Cooperación Económica Asia Pacífico (APEC), que es el principal organismo de cooperación económica, intercambio e inversiones en la región. Esta región es desde la década de los ochenta la región más dinámica, liderada en principio por Japón, más tarde por Corea del Sur y recientemente por la República Popular China.

Una de las características de las economías que conforman el APEC, es precisamente que basan su fortaleza en su dinámica exportadora más que en la importadora. En lo general son economías orientadas a los mercados externos, sobre la base de la conducción del Estado y la activa participación del sector privado. En la gráfica 5 se observa dicho dinamismo, que no obstante que ha disminuido en la última década, aún representa alrededor de $85 \%$ del comercio mundial total. 
GRÁFICA 5. Porcentaje de participación del APEC en el comercio mundial (1948-2017)

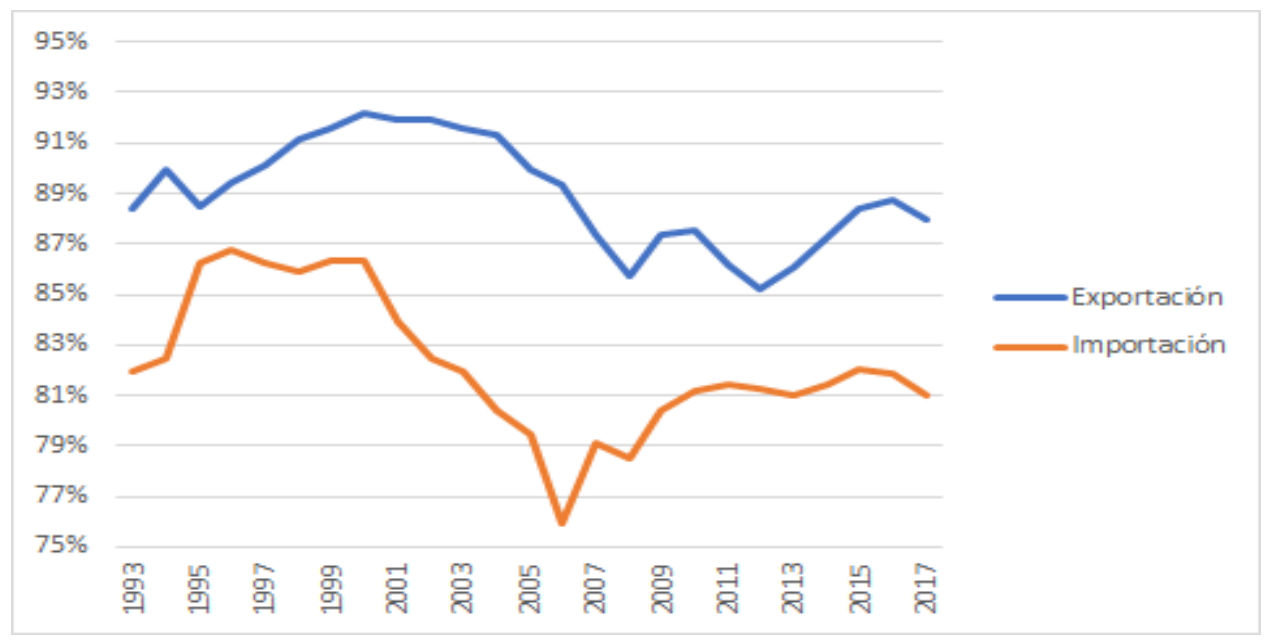

FUENTE: Elaboración propia con datos de la Subsecretaría de Comercio Exterior (2018b).

Obviamente dicho porcentaje se explica en gran medida porque en esa región se encuentran las dos principales economías del mundo, EUA y China, más Japón, que es la tercera economía mundial. En sí, es China quien ha propiciado el resurgimiento de la región Asia-Pacífico, toda vez que Japón cayó en un aletargamiento desde finales de la década de los ochenta. China pues, desde 2011 desplazó a EUA como la locomotora del comercio en la región, y hoy es prácticamente el principal socio comercial, superavitario, de la mayoría de los países del mundo, y de Asia-Pacífico en particular, donde tiene a sus principales socios comerciales. 
GRÁfICA 6. Porcentaje de China y EUA en el comercio total del APEC (1948-2017)

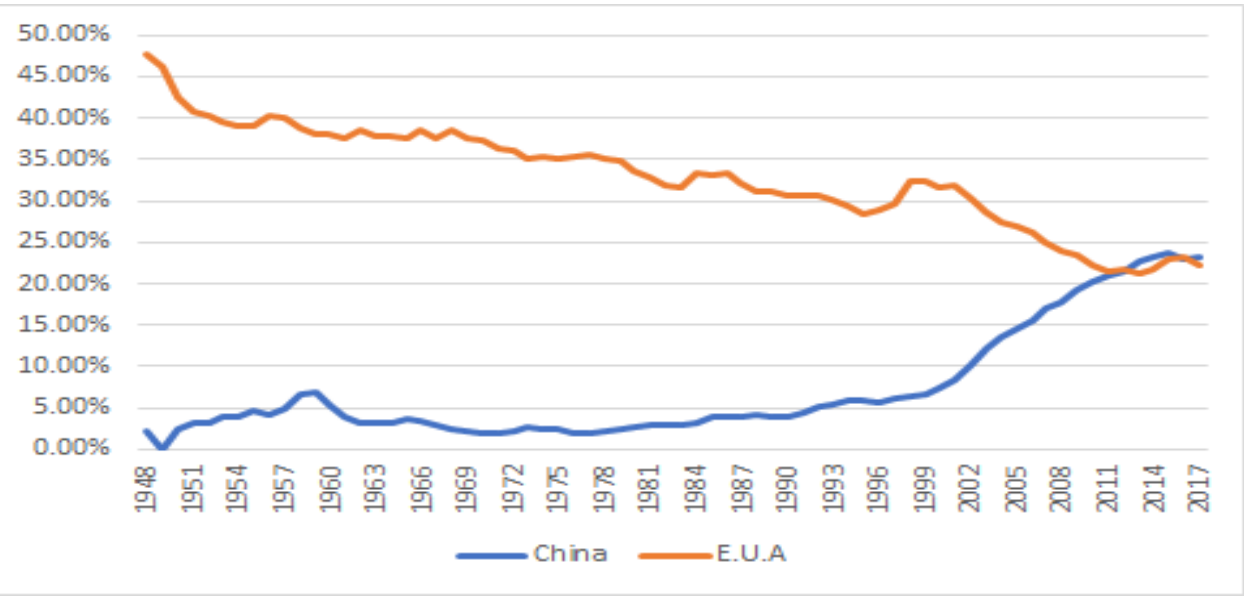

FUENTE: Elaboración propia con datos de la UNCTAD Stat, 2018.

Ahora bien, el dinamismo de China se refleja en el comercio internacional, sobre todo a partir de su membresía con la OMC en 2001, año que marca su entrada a los grandes flujos del comercio internacional, basado en su estrategia de reforma y apertura externa iniciada en 1978. Desde entonces China se convirtió, como ya se mencionó en la locomotora del comercio mundial, principalmente en la parte de las exportaciones intensivas, tanto en sus ventajas comparativas como, recientemente, en su gran producción industrial y tecnológica.

Desde el punto de vista de la región Asia-Pacífico como un todo, ésta representa para México todavía una gran incógnita que no ha sabido resolver, ya que desde 1993 hasta la actualidad (2018) registra un saldo negativo en su relación comercial, que lejos de disminuir, crece año con año. Dicho déficit es mayor con los tres países más importantes de la región Asia-Pacífico que pertenecen al APEC, independientemente del comercio con EUA, debido al dinamismo que conjuntamente mantienen China, Japón y Corea del Sur, quienes, junto con Estados Unidos, son los cuatro países de la región con los que se concentra el grueso del comercio regional de México (gráfica 7). 
GRÁFICA 7. Importaciones de México con la APEC (1993-2017)

$$
\text { (miles de dólares) }
$$

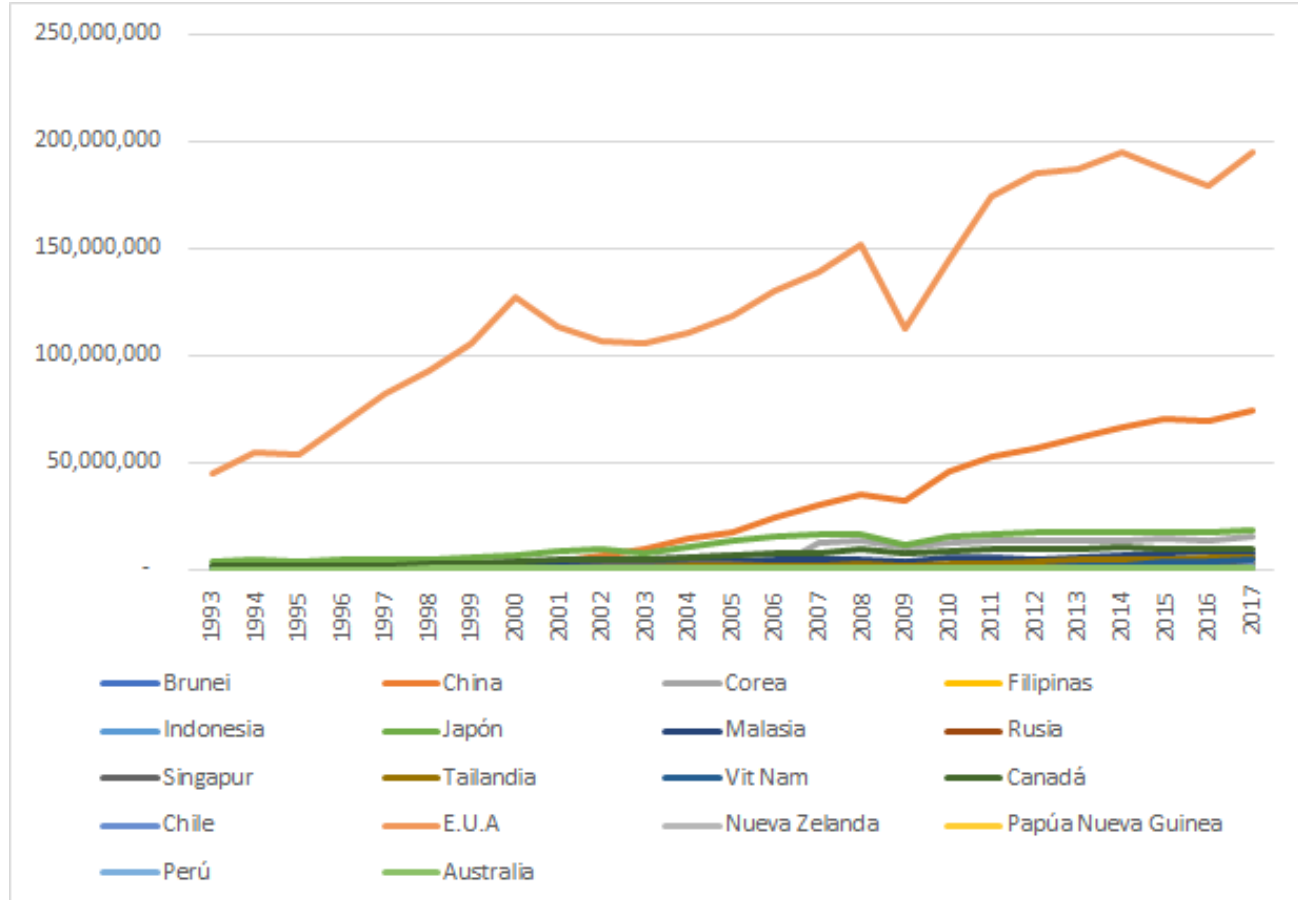

FUENTE: Elaboración propia con datos de la Subsecretaría de Comercio Exterior (2018b).

Por otra parte, como ya se dijo, la APEC y en general la región Asia-Pacífico es el gran reto y oportunidad que tiene México para tratar de revertir su déficit comercial y a su vez diseñar e implementar una política comercial estratégica que le permita buscar el equilibrio en el mediano y largo plazos. Es ésta la gran oportunidad que el país debe aprovechar para no seguir dependiendo de un solo mercado en relación con la mayoría de los países de la región, sino ser origen de las exportaciones más dinámicas que, se espera, el país producirá.

En efecto, como se puede observar en la gráfica 8, fuera de EUA las exportaciones de México hacia la región Asia-Pacífico, particularmente de las economías de la APEC, es irrelevante y éstas se concentran principalmente en China, Japón y Corea del Sur. Fuera de estos países, las demás economías no representan ni 1\% del comercio con Asia. 
GRÁFICA 8. Exportaciones de México con la APEC (1993-2017)

$$
\text { (miles de dólares) }
$$

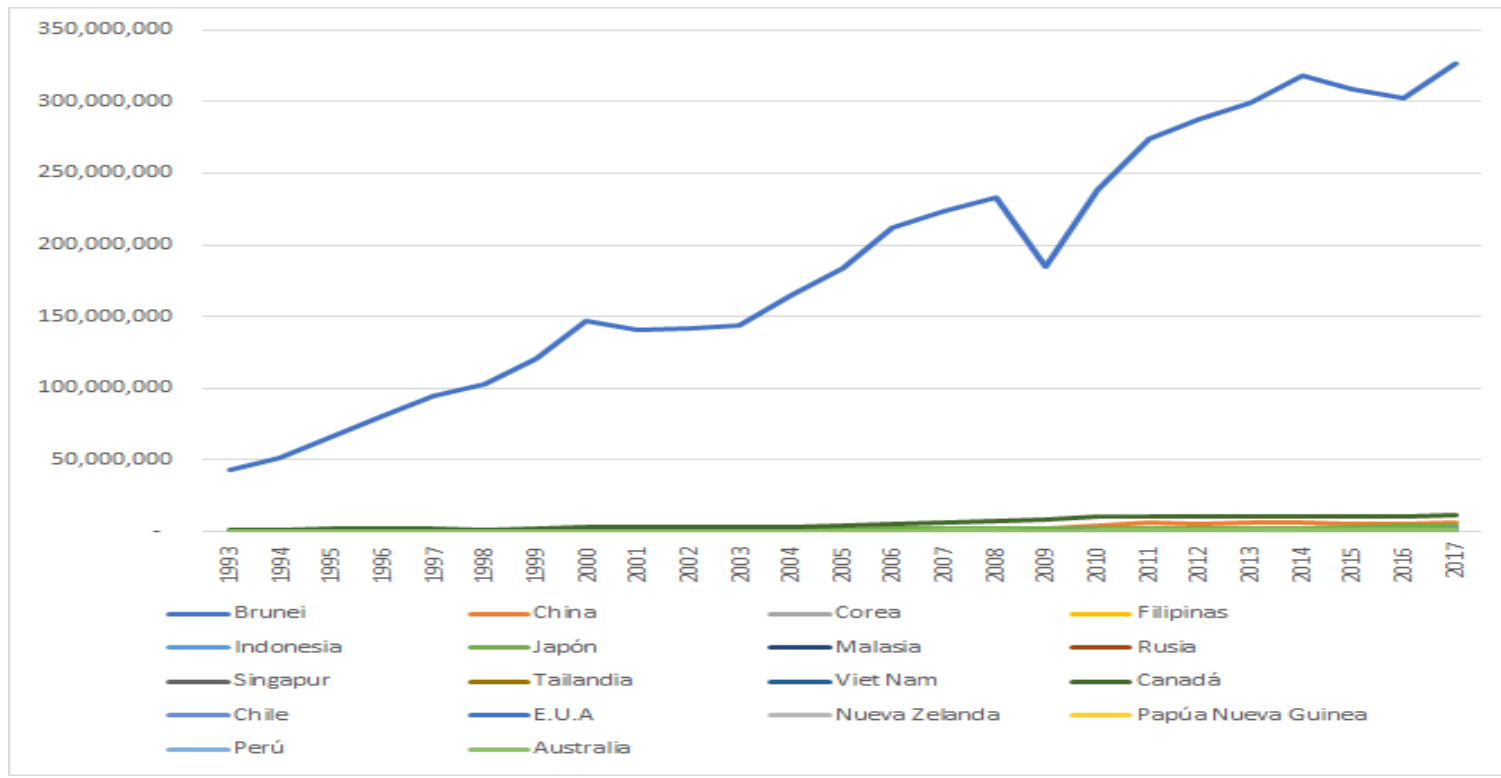

FUENTE: Elaboración propia con datos de la Subsecretaría de Comercio Exterior (2018b).

China, Japón y Corea del Sur deberían ser los referentes principales en los que México debe poner atención a la hora de redefinir una política comercial estratégica, y aunque de momento son los países en los que se concentra $80 \%$ del déficit comercial de México con la región Asia-Pacífico y las economías de la APEC, es con ellos con los que ya existe una relación económica desde hace varias décadas y a los cuáles México no ha puesto la atención debida.

Excepto Japón, con quien se tiene incluso un Acuerdo de Asociación Estratégica desde 2005, con Corea del Sur no se ha avanzado sobre un posible acuerdo comercial desde 2004, y ni qué decir de China, país con el que se ha tenido una relación económica y política de confrontación en los últimos años, la cual podría cambiar hacia nuevos estadios de entendimiento dada la disposición de ese país de iniciar pláticas para la firma de un posible acuerdo comercial.

Desde nuestro punto de vista, el noreste asiático podría ser el punto de partida de una nueva política estratégica de comercio internacional, en los términos aquí planteados, que son priorizar, a partir de un conocimiento efectivo de las causas que dieron lugar a los magros 
resultados en términos de comercio e inversión diversificados. Para ello no basta sólo enunciarlo, sino ir a fondo en las causas y formular la propuesta estratégica, así como las acciones, que habrán de ser fundamentales para hacer factible la diversificación comercial internacional.

En principio, es importante saber que los vínculos comerciales con el noreste asiático han evolucionado de manera creciente desde la década de los noventa, ya que en los ochenta, principalmente el comercio con dicha triada, se realizaba básicamente con Japón. A partir de los noventas, es con los tres países con quiénes se concentra $80 \%$ del comercio total de México con la región Asia-Pacífico y la APEC oriental. Esto se observa en la gráfica 9, que muestra cómo fue en la década de los noventa, cuando dio inicio la tendencia a la alza de dicho comercio, el cual prácticamente se ha triplicado en relación con los intercambios de México con Japón, con quién se realizaba casi 90\% del intercambio con la región del noreste asiático.

GRÁFICA 9 Evolución del comercio de México con China, Corea del Sur y Japón, respecto al comercio del mundo

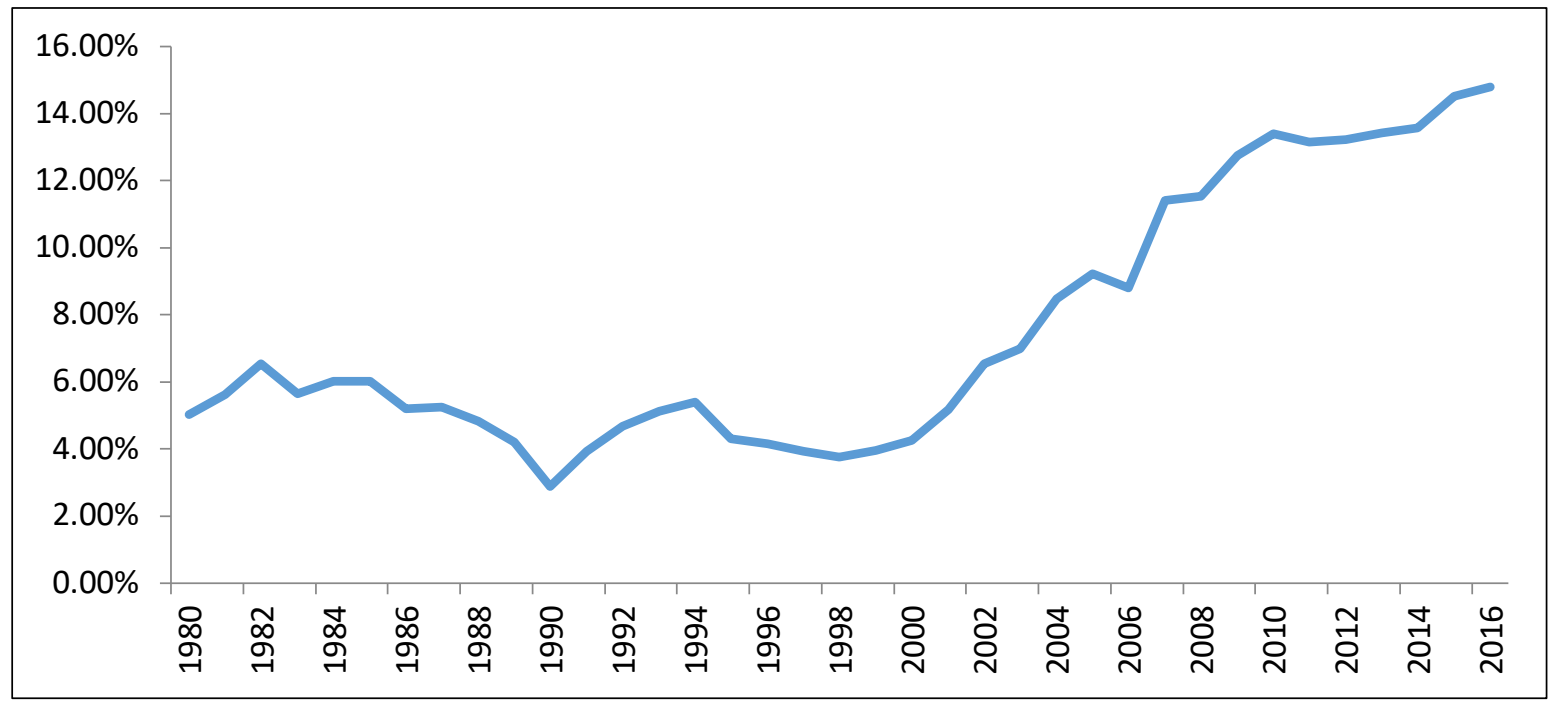

FUENTE: Elaboración propia con datos del INEGI (2015), el Banco Mundial (2017) y el Banco de México (2017).

La gráfica 10 permite constatar la evolución del comercio de México con el noreste asiático, particularmente en dos aspectos: a) que en la década de los ochenta, previo a la apertura comercial mexicana y al despegue del modelo asiático exportador ampliado con 
Corea del Sur, los llamados Nuevos Países Industrializados (NIC) y posteriormente China, crecen a tasas superiores a 5\%. Con la plena incorporación de China al comercio internacional, derivado de su ingreso a la OMC, se presenta un segundo fenómeno: b) el creciente déficit comercial que registra México con estos tres países, particularmente con China, que desplaza a Japón del primer lugar como socio comercial de México con el noreste asiático.

GRÁFICA 10. Evolución de las exportaciones e importaciones con China, Corea del Sur y Japón en el periodo 1980-2016

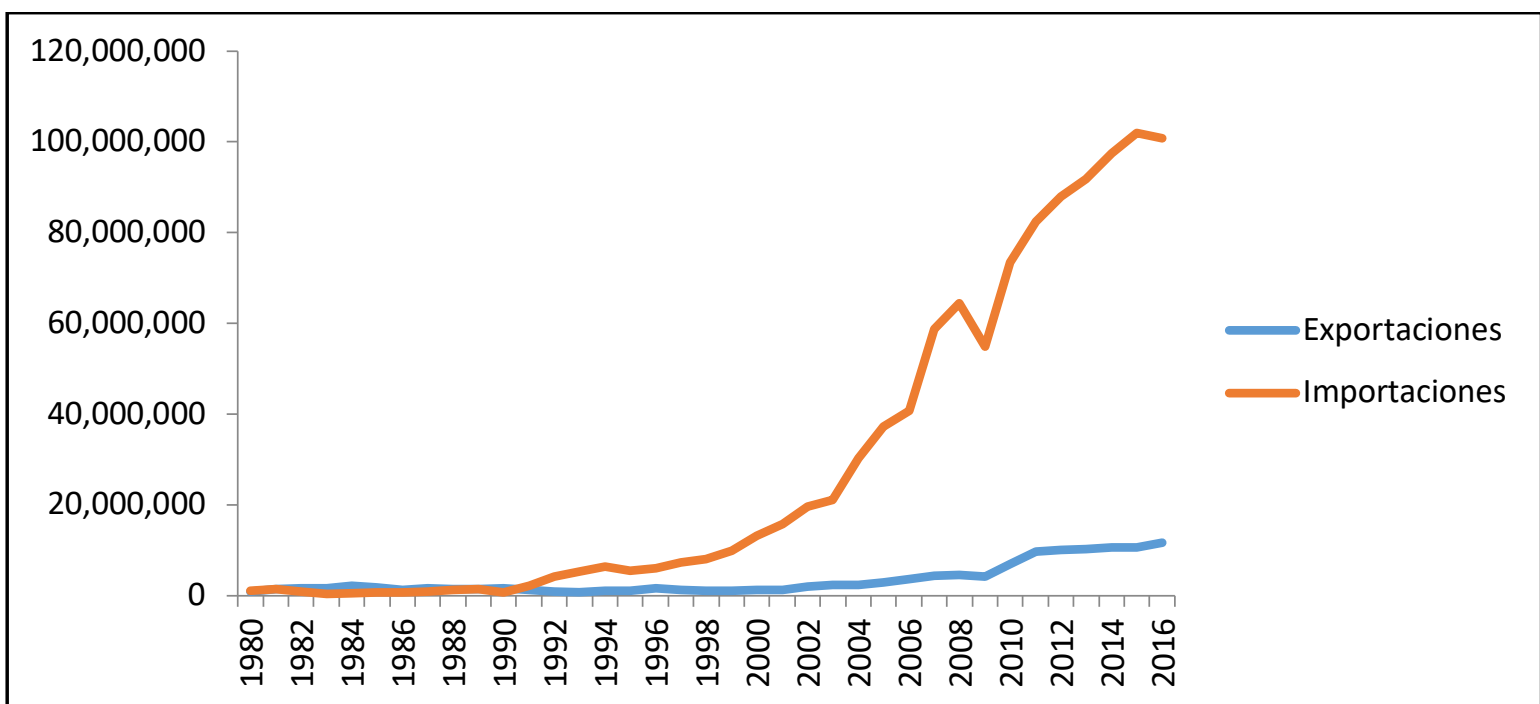

FUENTE: Elaboración propia con base en información de la Secretaría de Economía (2018).

Es China el país con el que se tiene el principal déficit comercial de la región y el que se ha convertido en el segundo socio comercial de México, sólo detrás de EUA, con la característica de que, a diferencia del saldo superavitario que acumula México con EUA, sobre todo a partir del TLCAN, con China se registra una situación contraria: es el país con el que acumula el mayor déficit comercial del mundo. China se constituye, entonces, en el principal reto a vencer para México, derivado del hecho de que durante años fue un país competidor en los mercados de exportación mexicanos, y en el mercado de EUA, del que fue desplazado desde 2003 y con el que acumula un déficit superior a los 200 mil millones de dólares. 
GRÁFICA 11. Evolución de la balanza comercial de México con China, Corea del Sur y Japón

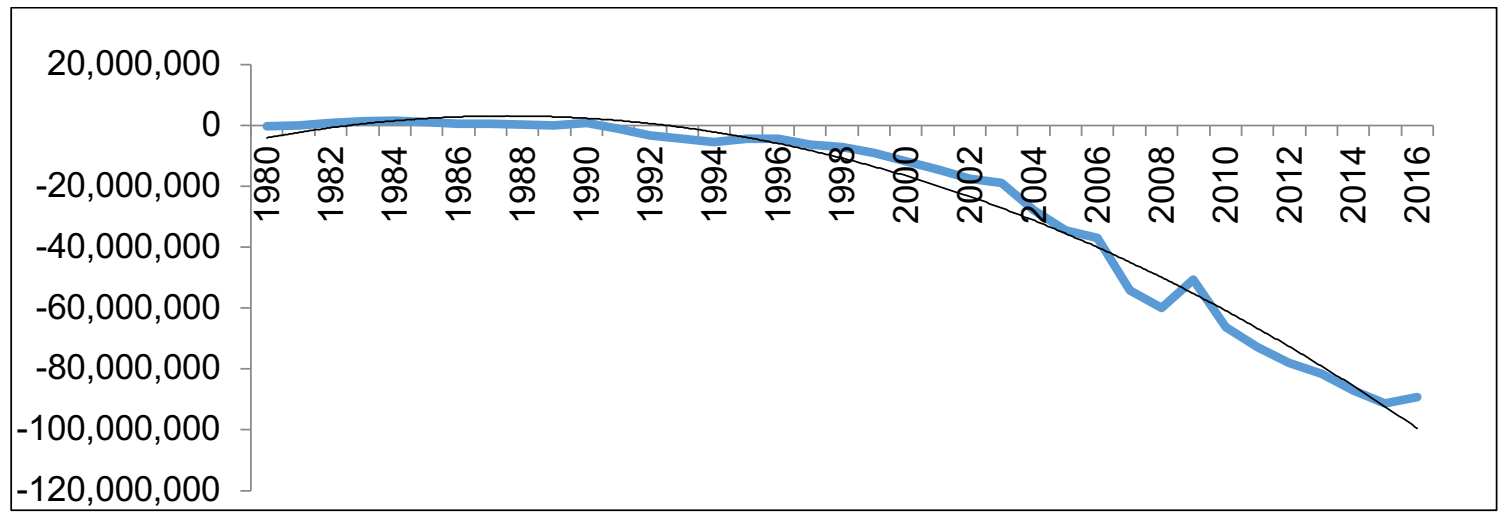

FUENTE: Elaboración propia con datos del INEGI (2015), el Banco Mundial (2017) y el Banco de México (2017).

El comercio de México con el noreste asiático se concentra en bienes intermedios, minerales, y en algunos energéticos por parte de México, así como en bienes manufacturados e intermedios por parte de Japón, China y Corea del Sur, en ese orden. Sólo de algunos años a la fecha (desde 2005, para ser exactos) México ha ampliado su canasta de bienes de exportación, al incluir artículos primarios de reciente demanda en Asia Oriental, como: carnes, de res, puerco y pollo; aguacate, jitomate, berries, tequila, mezcal y cerveza.

Lamentablemente las exportaciones mexicanas a Asia-Pacífico son de bienes tradicionales, sujetos a los vaivenes de los precios internacionales y de poco valor agregado industrial; esto pone en jaque a México ante movimientos a la baja en la demanda internacional de sus bienes exportados. A partir de lo anterior, es imprescindible que México elabore de inmediato una política comercial estratégica que le permita diversificar la base de sus productos exportables, incluyendo aquellos de base tecnológica e intensivos en capital.

Además, es importante también que realice estudios a profundidad, o de gran alcance comercial, en los que se analice realmente cuál es la capacidad comercial del país para generar una canasta y base exportadora que le permita incursionar en los mercados asiáticos apoyado en las variables de precio, calidad, servicio y potservicio o postcompra, en caso de ser necesario, para saber cuál es su verdadera capacidad de oferta exportable, a la par de realizar estudios in situ de los productos y servicios que principalmente está demandando Asia-Pacífico en la actualidad, y, sobre todo, prever dicha demanda internacional y su 
crecimiento a futuro. Sólo procediendo de esta manera México podrá redefinir su nueva incorporación al grupo Asia-Pacífico de manera realista y ya no más como una simple aspiración y/o enunciado de una política comercial internacional estratégica que ha estado ausente por años e incluso décadas.

Sólo de esta manera, con una política comercial internacional estratégica de nuevo cuño, es posible esperar que México logre cambiar el statu quo de su dependencia económica y comercial hacia un solo mercado internacional y empiece a hacer verdaderamente efectiva la diversificación comercial de mercados y territorios para los bienes y servicios que se producirán a futuro en el país. La región Asia-Pacífico sigue siendo un gran reto, como ya lo planteaban algunos estudios del fenómeno cuenca del Pacífico desde la década de los noventa.

\section{CONCLUSIONES}

Antes de escribir este artículo, la firma del nuevo acuerdo comercial de México con Estados Unidos y Canadá era todavía un asunto inconcluso; sólo hace unos días (el 30 de agosto de 2018) terminó la negociación de la parte preejecutiva, por medio del proceso de negociaciones que realizaron funcionarios de alto nivel de los tres países, para renovarlo o “modernizarlo". En sí, la renegociación del TLCAN, o como ahora se le está llamando, USMCA, fue el motivo principal que nos llevó a realizar esta investigación y a proponer su estructura metodológica de desarrollo argumentativo. En la actualidad ya se firmó el acuerdo, desde el punto de vista preejecutivo de los tres países; falta solamente su entrega a los respectivos congresos legislativos de dichos países, para su ratificación, enmiendas o rechazo.

Seguramente antes de que se hagan públicos los detalles del nuevo acuerdo comercial, USMCA, habrá varias incógnitas a desvelar conforme se discuta en los respectivos congresos los pros y los contras del mismo. Pero independientemente de estos tópicos, lo que en realidad interesa saber es si México va a tener la suficiente visión, decisión y convicción para definir una nueva estrategia comercial internacional, hablando en términos generales, para el mundo y en particular para Asia-Pacífico, pues centrar sus intercambios comerciales principalmente en un solo país, como ha sido hasta ahora, es asumir una vez más la dependencia per se de un solo mercado. 
La nueva política de comercio internacional estratégica de México necesariamente tendrá que considerar algunos de los elementos o factores que en este escrito se han listado, tanto internos como externos, para afrontar los nuevos retos por venir de la década de 2030 y que tienen que ver, en esencia, con hacer efectiva la diversificación comercial. Para ello, ya no debe nunca más concebirse a la política comercial como subpolítica, que por sí sola logrará los objetivos y metas del comercio exterior mexicano, ya que, como se analizó en este escrito, no se relaciona de suyo con el engranaje de un modelo de desarrollo económico que si bien busca tener presencia en el mercado internacional, también debe fundamentarse en la estructura industrial, económica, financiera, tecnológica, educativa y de infraestructura física y logística, dentro de los factores internos. De otra manera, significaría seguir con aspiraciones irrealizables.

Además, en lo externo se debe dar ya el salto adelante para propiciar una verdadera inserción en los mercados internacionales de los países que mayor crecimiento económico y comercial están teniendo, puesto que ello es una condición sine qua non para diseñar una estrategia comercial por país o por región que permita contar con una visión nítida del dinamismo del mercado interno de dichos países y/o regiones, sin suponer que el solo hecho de ser miembros de la OMC o de contar con un acuerdo comercial es suficiente para pensar que la conquista de los mercados externos es un asunto de mero voluntarismo políticodiplomático que pronto se logrará.

En la actualidad ya no es posible pensar que sin impulsar la productividad de los factores de la producción, la competitividad de las empresas y gobiernos; sin estudios in situ de empresas y gobiernos; sin hacer acto de presencia en los mercados globales, regionales y nacionales; sin conocer los hábitos de consumo y las tendencias de consumo de los países meta, se van a poder alcanzar los objetivos de diversificación comercial. No puede haber decisión más errada que pensar de la manera arriba descrita, aún más, es momento de canalizar toda la experiencia acumulada por más de tres décadas de fracasos y malas decisiones, para rescatar lo poco que sí se ha logrado diversificar, así haya sido marginalmente.

Concluimos este breve escrito señalando que el objetivo del mismo no ha sido otro que contribuir con una reflexión crítica, objetivamente argumentada en torno a lo que no se ha hecho en estas décadas de apertura para lograr la tan ansiada diversificación comercial a fin 
de que sirvan de referente y puedan incidir en los tomadores de decisiones para que redefinan la política comercial internacional, realmente estratégica, que nuestro país requiere, y que lleve a lograr sus objetivos de verdaderamente convertirse en una potencia exportadora, como señalan los postulados que se planteaban en la década de los ochenta, cuando empezó la aventura exportadora mexicana.

\section{REFERENCIAS BIBLIOGRÁFICAS}

Banco Mundial (2017), Estadísticas históricas del comercio. Recuperado de: https://datos.bancomundial.org/indicador/NY.GDP.MKTP.CD?locations=MX-CAUS

Banco de México (2017), Estadísticas, 6 de noviembre. Recuperado de: http://www.banxico.org.mx/estadisticas/index.html

Banxico (2018a), Balanza comercial de mercancías de México (1980 a 1992). Recuperado de:

http://www.banxico.org.mx/SieInternet/consultarDirectorioInternetAction.do?sector= $1 \&$ accion $=$ consultarCuadro\&idCuadro $=$ CE132\&locale $=$ es

Banxico (2018b), Balanza comercial de mercancías de México (sin apertura de maquiladoras). Recuperado de: http://www.banxico.org.mx/SieInternet/consultarDirectorioInternetAction.do?accion $=$ consultarCuadro\&idCuadro $=$ CE125\&sector $=1 \&$ locale $=$ es

Bendesky, L. (1994), “Economía regional en la era de la globalización”, Comercio Exterior, pp. 982-989.

Boisier, S. (2007), "Imágenes en el espejo: aportes a la discusión sobre el crecimiento y el desarrollo territorial”, Ciencias Sociales Online, vol. 4, núm. 2, Chile, Universidad Villa del Mar, pp. 183-187.

Calderón, C. y I. Sánchez (2012), "Crecimiento económico y política industrial en México", Problemas del desarrollo, vol. 43, núm. 170, UNAM, julio-septiembre, pp. 125-154.

Calva, J. L. (2007), "Política industrial manufacturera”, Economía, UNAM, vol. 4, núm. 12, UNAM, p. 132. 
Cárdenas, E. (2015), "La crisis de la estrategia y el estancamiento de los ochenta, 1982-1988". El largo curso de la economía mexicana. De 1780 a nuestros días, México, FCE/El Colegio de México, pp. 640-698.

Cimoli, Mario, Giovani Dosi y Joseph Stiglitz (2017), "Políticas industriales y tecnológicas en América Latina", CEPAL. Recuperado de: https://www.cepal.org/es/publicaciones/42363-politicas-industriales-tecnologicasamerica-latina

Esquivel, G. (2012), "De la inestabilidad macroeconómica al estancamiento estabilizador: el papel del diseño y la conducción de la política económica", Los grandes problemas de México. Economía, México, El Colegio de México, pp. 17-20.

González García, J. (1994), "La cuenca del Pacífico: ¿una opción real de diversificación comercial?, en Ernesto H. Turner Barragán et al. (coords.), México en los noventa: globalización y reestructuración productiva, UAM-Azcapotzalco/Universidad Michoacana de San Nicolás de Hidalgo, pp. 109-130.

González García, J. (1995), "La relación comercial de México con la cuenca del Pacífico: el comercio bilateral como vía para la integración económica", en A. Sánchez Daza y J. González García (coords.), Reestructuración de la economía mexicana. Integración a la economía mundial y la Cuenca Pacífico, México, Universidad de Colima/UAM/RNICP, pp. 127-142.

González García, J. y J. S. Meza Lora (2008), “La política industrial en el siglo XXI y la nueva economía institucional”, Comercio Exterior, vol. 58, núm. 11, pp. 769-779.

Heras Villanueva, M. y C. Gómez Chiñas (2017), "Perspectivas y prospectivas de la política industrial en México", Análisis Económico, vol. 32, núm. 79, pp. 77-98.

Herrera Martínez, L. E. (2004), Los acuerdos de libre comercio en la política comercial mexicana: a la luz de sus objetivos, contenidos y tendencias, España, Universidad Autónoma de Barcelona-Facultad de Ciencias Políticas y Sociología- Departamento de Ciencia Política y Derecho Público.

INEGI (2015), Estadísticas históricas de Mexico, 17, sector externo, México, pp 37-39. 
Krugman, P. (2011), The New Economic Geography, Now Middle-Aged. Regional Studies, vol. 45, núm. 1, pp. 1-7.

Krugman, P., R. N. Cooper y T. N. Srinivasan (1995), "Growing World Trade: Causes and Consequences”, Brookings Papers on Economic Activity, vol. 26, núm. 1, pp. 327-377.

Martínez Ortiz, Astrid y José Antonio Ocampo (2011), Hacia una política industrial de nueva generación para Colombia, Bogotá, Coalición para la Promoción de la Industria Colombiana, p. 107.

Moreno Brid, J. C. (2016), "Política macro e industrial para un cambio estructural y crecimiento: gran pendiente de la economía mexicana”, Problemas del Desarrollo, vol. 47, núm. 185, UNAM, abril-junio, pp. 59-80.

Mortimore, M., R. Buitelaar y J. L. Bonifaz (2000), México: Un CANálisis de su competitividad internacional, serie Desarrollo Productivo, núm. 62, Santiago de Chile, CEPAL, pp. 7-72.

Ocegueda Hernández, J. M. (2007), “Apertura comercial y crecimiento económico en las regiones de México", Investigaciones Económicas, vol. 16, núm. 262, pp. 89-137.

Ocegueda Hernández, J. M. y J. A. Ríos-Flores (2017), "Capacidad innovadora y crecimiento regional en México: un enfoque espacial”, Economía, Sociedad y Territorio, vol. 17, núm. 55, pp. 743-776.

Organización Mundial del Comercio OMC (2018), Paradigm lost? US Trade Policy as an Instrument of Foreign Policy, Recuperado de: https://www.wto.org/spanish/news_s/news18_s/ddgra_09feb18_s.htm

OMC (2018), "Lista de todos los ACR, incluyendo las adhesiones a los acuerdos". Recuperado de: http://rtais.wto.org/UI/PublicMaintainRTAHome.aspx

Ortiz Cruz, Etelberto (2009), “Características estructurales de la crisis actual. Definiendo una nueva agenda para el cambio estructural”, Economía: Teoría y Práctica, vol. 2, pp. 4156. 
Perrotini Hernández, I. y J. A. Vázquez-Muñoz (2018), “El super multiplicador, la acumulación del capital, las exportaciones y el crecimiento económico", Trimestre Económico, vol. 85, núm. 338, pp. 411-432.

Puyana, A. y J. Romero (2004), "La estrategia comercial mexicana ¿Superando la fuerza centrípeta estadounidense?”, Foro Internacional, vol. 44, núm. 177, pp. 392-429.

Rodrik, D. (2004), Industrial Policy for the Twenty-First Century, John F. Kennedy School of Government, Harvard University, pp. 1-42.

Rodrik, D. (2005), "Políticas de diversificación económica", Revista de la CEPAL, núm. 87, pp. 7-23.

Rodrik, D. (2008), Normalizing Industrial Policy, Washington DC, Banco Internacional de la Reconstrucción y Desarrollo-Banco Mundial, pp. 1-36.

Rubinstein, A. (2017), “Comments on Economic Models, Economics, and Economists: Remarks on Economics Rules by Dani Rodrik”, Journal of Economic Literature, vol. 1, núm. 55, pp. 162-172.

Ruiz Durán, C. (2011), “Crisis financiera de principios del siglo: variedades de capitalismo, respuestas territoriales en la economía global”, Economía, UNAM, vol. 8, núm. 24, pp. 3-22.

Schumpeter, J. A. (1978), Teoría del desenvolvimiento económico, México, Fondo de Cultura Económica, pp. 7-255.

Secretaría de Economia (SE) (2018), Información estadística y arancelaria. Recuperado de: https://www.gob.mx/se/acciones-y-programas/comercio-exterior-informacionestadistica-y-arancelaria? state $=$ published

SICAIT (2018), Tratados y acuerdos interinstitucionales suscritos por México bajo la coordinación o responsabilidad de la Secretaría de Economía. Recuperado de: http://economia-snci.gob.mx/sicait/5.0/

SICE (2018), Información sobre México: Acuerdos comerciales en vigor/suscritos aún no vigentes. Recuperado de: $<$ http://www.sice.oas.org/ctyindex/MEX/MEXagreements_s.asp>. 
Subsecretaría de Comercio Exterior (2018a), Acuerdos y tratados comerciales suscritos por México. Recuperado de: https://www.gob.mx/cms/uploads/attachment/file/1883/Cuadro_de_Acuerdos_y_Trat ados_Comerciales_de_Mexico.pdf

Subsecretaría de Comercio Exterior (2018b), Sistema de consulta de información estadística por país. Recuperado de: http://www.economiasnci.gob.mx/sic_php/pages/estadisticas/

Thirlwall, A. (2011), "Balance of Payments Constrained Growth Models: History and Overview”, PSL Quarterly Review, vol. 64, núm. 259, pp. 307-351.

UNCTAD (2018a), Adaptar las políticas industriales al mundo digital para favorecer la diversificación económica y la transformación estructural. Recuperado de: https://unctad.org/meetings/es/SessionalDocuments/cimem8d5_es.pdf

UNCTAD (2018b), Adaptar las políticas industriales al mundo digital para favorecer la diversificación económica y la transformación estructural, Ginebra. p. 15.

UNCTAD (2018c), Data Center, Recuperado de: http://unctadstat.unctad.org/wds/ReportFolders/reportFolders.aspx?sCS_ChosenLang $=$ en

UNCTAD (2018d), The Costs of Trade War. Recuperado de: https://unctad.org/en/pages/newsdetails.aspx?OriginalVersionID=1784

UnCTAD Stat (2018), Merchandise: Total Trade and Share, Annual. Recuperado de: http://unctadstat.unctad.org/wds/TableViewer/tableView.aspx?ReportId=101

WITS (2018), Mexico sitc rev2 products export product share \% world 1990-2016. Recuperado de: https://wits.worldbank.org/CountryProfile/en/Country/MEX/StartYear/1990/EndYear /2016/TradeFlow/Export/Indicator/XPRT-PRDCT-SHR/Partner/WLD/Product/sitcrev2-groups

WTO (2018), World Trade Report 2018, Ginebra Suiza, pp. 1-236. 